\title{
Islamic Moral Judgement on Resuscitation Issue: Nursing Perspective
}

\author{
Mohamad Firdaus bin M. Ismail ${ }^{1}$,Abdurezak A. Hashi ${ }^{2}$, Mohd Said bin Nurumal, ${ }^{1}$ Muhammad Lokman bin Md \\ Isa. ${ }^{1}$ \\ ${ }^{1}$ Kulliyyah of Nursing, International Islamic University Malaysia Kuantan. \\ ${ }^{2}$ Kulliyyah of Science, International Islamic University Malaysia Kuantan.
}

\begin{abstract}
The primary goals of resuscitation are to preserve life, restore health, relieve suffering and limit disability. As nurses, executing the cardiopulmonary resuscitation (CPR) to a patient experiencing cardio-pulmonary arrest is essential in preserving life. However nurses face a dilemma in the decision making to either preserve the patient's life or let the patient die naturally, if the patient's autonomy as well as his family's wish for a "do not resuscitate (DNR)" order. In this dilemma, the sanctity of life and the right to die is the main concern of this discussion. Islamic moral judgment, as the major concern here, should be studied as an alternative to analyse and provide a guideline that is in accordance with the Islamic teaching. Thus, this research is to provide the Islamic moral judgment on the resuscitation issue and its implication in nursing practices. The western ethics that represent the current practices on resuscitation is not included. The comparison was then made with the ultimate origin of Islamic teaching ie the Qur'an and Sunnah, as well as the notions of Muslim scholars on the subject. As the physician opines that CPR is to be beneficial to rescue a life, therefore refusing it may be considered as immoral. However, the DNR order is entirely acceptable if the doctor believes that CPR is futile and gives no benefit to the patient. The doctor has the authority to issue a DNR order if he is certain that the patient would not benefit from CPR without getting consent from the patient or his relative. Nursing implications: As nurses facilitate patients and family members in forming a decision about end of life hence engaging a comprehensive view of DNR based on Islamic teaching would provide an informed choice when advising a Muslim patient and family. The area to investigate would be on the degree of knowledge among nurses regarding the Islamic moral judgement on this matter is highly recommended for future management.
\end{abstract}

KEYWORDS: Resuscitation, Nursing, Islamic teaching.

\section{DEFINITION OF RESUSCITATION}

According to Macmillan English Dictionary, 'resuscitate' means to make an unconscious person able to breathe once more. ${ }^{1}$ The American Heritage Science Dictionary associates resuscitation to 'the restoration of consciousness, vigour or life'. In the clinical setting, it refers to cardiopulmonary resuscitation, known as CPR. ${ }^{2}$ The word 'cardio' denotes the heart, while 'pulmonary' means the lung, whilst 'resuscitation' signifies the artificial respiration that is planned to restore consciousness. In order to presume consciousness, breathing and blood circulation are the critical components that need to be stressed. Blowing air into the lung may help the patient in breathing, whereas chest compression may help with blood circulation in the body. Both processes are essential in maintaining the flow of oxygenated blood to vital organs until the person's heartbeat and breathing can be resumed. ${ }^{3}$ Thus, to provide a

Corresponding author:

Mohamad Firdaus bin M. Ismail

Kulliyyah of Nursing

International Islamic University Malaysia

Jalan Sultan Ahmad Shah, 25200 Kuantan, Pahang

Email: firdausismail@iium.edu.my comprehensive definition of CPR, it is worth to mention that despite blowing air and chest compression, the patient may be supported with medication and a ventilator to stabilise his physiological and metabolic changes. As written in a hospital guideline written for patients and families in New York State, "CPR may involve simple efforts such as mouth-to-mouth resuscitation and external chest compression. Advanced CPR may involve electric shock, insertion of a tube to open the patient's airway, injection of medication into the heart, and in extreme cases, open chest heart massage." 4

\section{Basic Concepts of Resuscitation and Do Not Resuscitate}

Established in the study made by the National Registry of Cardiopulmonary Resuscitation on 14,720 reports of cardiac arrest patients, most cardiac arrest cases were are due to cardiac arrhythmia, acute respiratory insufficiency and hypotension. ${ }^{5}$ Whenever the patients suffer from cardiac or respiratory arrest, automatically a code blue will be activated and CPR will be performed as a standard practice for all patients unless there is a verbal or written document mentioning otherwise. This verbal or written document is best recognised as a healthcare advance directive for most of the 
states. Nevertheless, the verbal order is not taken as the standard practice. A healthcare advance directive is a legal binding document such as in the United States (US) and Britain; it is based on the Patient Self-Determination Act of $1990^{6}$ and Mental Capacity Act $2005^{7}$ respectively. Unfortunately, in Malaysia currently there is no legislation bound to the healthcare advance directive. ${ }^{8}$ The healthcare advance directive provides the wishes or preferences of a patient given at a time when a person holds the capacity for healthcare decision to be applied when the person has later lost capacity. ${ }^{9}$ An advance directive is considered significant because it can be used to counter the decision made by the family which could be against the will of the patient. It can also prevent conflict among family members and protect healthcare providers from lawsuits. Healthcare advance directive consists of two types namely; living wills and healthcare power of attorney. A living will is a document that informs healthcare providers of the kind of treatment that should be provided or withheld to the individual. In the US under the state law, the living will only take effect when the patients are diagnosed near to dying after suffering from terminal illnesses or are permanently comatose; and they cannot communicate their preference to a healthcare provider. ${ }^{10}$ For instance, a terminally ill patient informs the physician that he or she refuses to be resuscitated and prefers to die naturally hence the physicians have to respect the autonomy of the patient in making the decision by either withholding resuscitation or passing that case to another physician who will honour the patient's.

The second type is a healthcare power of attorney. This is a document that identifies healthcare agent as the decision maker on behalf of the incapacitated patient particularly when the patient is terminally ill or comatose. ${ }^{11}$ Patient's family members, particularly the parents as well as their close friends are also included in these types of advance directive. Most of the patients believe that healthcare power of attorney may establish a realtime decision on their behalf. Decision by the healthcare power of attorney may conflict with the living will but they are considered to be a valid expression of the patient's best interest for that particular time. ${ }^{12}$ Studies in the US by Emanuel \& Hummel in year 1993 found that the proportion of patients who have a living will in a written document was low. ${ }^{13}$ Similarly, in a study done in North Carolina by Hanson et al. in year 1994 found that most of the end of life decision for the patient were decided by the patient's family members. Based on these finding, a healthcare provider may have difficulty in making the actual decision for CPR in the absence of the patient's family members. ${ }^{15}$

For the major focal point of this discourse, advance directives are used to convey the patient's and families' preference in treatment, including whether to proceed with resuscitate if and when the patient suffers from cardiac or respiratory arrest. The aim of CPR is to save the patient but the evidence shows that the implementation of CPR does not ensure a high rate of survival to hospital discharge. ${ }^{16-18}$ In view of this, a policy was developed to limit the use of CPR and in carrying out the DNR order. This policy came about following the Quinlan case. $^{19}$ The Quinlan case revolved around the physician and the patient's father to determine whether to stop the treatment, in which the father was inclined to end his daughter's life. This case was settled when the New Jersey Supreme Court decided that Joseph Quinlan has the right to withhold his daughter's life-saving measure. This case set the precedent whereby the patient's right to refuse medical treatment as well as lifesaving intervention such as CPR has been widely acknowledged. ${ }^{20}$ Subsequently, DNR order then became one of the patient's right to stop attempts by the healthcare provider to resuscitate in the event of cardiac or respiratory arrest.

In healthcare practice, the term DNR refers to "do not resuscitate". Other similar orders are; "DNAR" (do not attempt resuscitation), "No Emergency CPR", "No Code" 21 and "DNACPR" (do not attempt cardiopulmonary resuscitation). ${ }^{22}$ Apart of that, the term "AND" (allow natural death) is becoming a preferred term to replace DNR to emphasise the order in allowing the natural consequences of a disease or injury to take place and the patient to die naturally. 23,24 Whilst a variety of terms have been suggested, throughout this discussion the term DNR will be used to refer to the preference of patient or healthcare power of attorney for 'do not attempt resuscitation'. It is likewise significant to note here that sometimes the term DNR is confusing since the interpretation varies between organisations. Some may interpret DNR as 'not performing CPR without intubation', whilst others may interpret DNR as 'utilising drugs only'. ${ }^{20}$ Likewise some people may interpret it by avoiding all lifesaving intervention such as intubation, chest compression and drugs. ${ }^{25}$ For most relevant interpretation, DNR orders might apply only to resuscitation. ${ }^{26}$ In other words, in the event of cardiac or respiratory arrest, there should be no attempt at resuscitation. Presuming no arrest occurs, the patient may recover from existing illness and be discharged from the hospital. In short, a true meaning of DNR clearly remains elusive. In a nutshell, DNR order may reflect the patient's preference to die naturally rather than having any extensive lifesaving intervention in the case of cardiac or respiratory arrest.

\section{Moral and Legal Dimension of DNR}

Though the application of DNR order is widely used, it is not free from any moral and legal arguments. The basic concept of the DNR order itself highlights the patient's preference to pass in the natural process rather than receiving life-saving intervention and the physicians' moral grounds to let it happen. It may raise several questions related to the sanctity of life and a patient's right. Is it morally correct for the physician to issue a DNR 
order for the patient or for the patient requesting it? In other words, some may suggest that the request for DNR is similar to avoid healing and preferring to die which is close to the concept of euthanasia.

In reference to this, Saleen Saiyad, in his reports in year 2009 stated that two different values between the healthcare provider and patient regarding the DNR order may result in a moral conflict. In one case example; Mrs. M, a 56 year old adult female who was admitted for abdominal pain and anaemia. Later, she developed multiple complications including gastrointestinal bleeding, fluid overload, respiratory failure and nosocomial pneumonia. After receiving multiple treatments, she developed further infection which progressed to renal failure requiring dialysis. Even though her quality of life reduced immensely, the ongoing treatment kept her alive. For this reason the physicians believed that the patient warrants DNR order. The family members however disagreed with the suggestion since the patient was not in terminal state unless the doctor believed that her renal failure as a terminal diagnosis. ${ }^{27}$

In this case, the two contradicting extremes in ethical arguments about issuing DNR order were unveiled ie. pro or against DNR order. From the perspective of supporting the DNR order, most of the articles reviewed were concerned about the patient's autonomy in which the patient has the right to refuse CPR and requests for the DNR order. ${ }^{28-32}$ In several countries namely the UK, US and Germany; the law allows the competent patient to refuse any form of healthcare treatment (Saevareid \& Balandin, 2011) including CPR whereby the refusal is morally acceptable if the patient was given a comprehensive explanation on the consequences of every decision taken. ${ }^{31}$ In short, healthcare providers including physicians and nurses should respect the patient's preference in his healthcare decision even if it contradicts their beliefs and values. Hence, the physician is responsible to document the patient's preference to refuse CPR or request DNR in the patient's medical file. ${ }^{28}$

Mark Hilberman et al. discussed that the principle of non-maleficence prohibits resuscitation if it produces more harm to the patient, thus issuing a DNR order is acceptable to (or "intending to") avoid further suffering of the patient. ${ }^{30}$ Similarly, if the physician believes that CPR is likely ineffective and only gives a minimal benefit to the patient, CPR may be considered as a futile treatment. ${ }^{28}$ Therefore, DNR is the best option for the patient in such situation. ${ }^{21,29}$ In most cases, a patient who is assigned with DNR order is usually; terminally ill, has poor prognosis or in the process of dying; whereby the condition is irreversible and a CPR attempt might give a poor outcome. ${ }^{20} \mathrm{~A}$ study carried out by Calam \& Andrew in year 2000 which used a retrospective chart review, demonstrated that the Prognosis After Resuscitation (PAR) score ie a tool predicting the likelihood of benefit from CPR have a significant correlation with the DNR order made by the physician. The result indicated the patient who obtained a score more than five ie poor prognoses such as metastatic cancer, sepsis and dependent functional status; is likely to be issued the DNR status by the physician. ${ }^{34}$ In terms of resource allocation, two studies have shown that there was significant reduction in resources used especially when the DNR order was issued early during the hospital stay. ${ }^{35,36}$ For instance, admission to the ICU should be offered only to the patient who will likely benefit from it. This evidence suggests that the seriousness of the condition of a patient can be a basis for the DNR order.

Other than the concern on the aspects of the medical condition, it is also believed that the DNR order helps patients prepare themselves mentally and emotionally to face death. Preparing for death has its ritual, which requires many family meetings, innumerable phone calls, lots of reassurance and a great deal of reinforcement. ${ }^{37}$ Perhaps this ritual is to ensure all the worldly matter that associated with the patient's life is completely settled and to respect the patient's wish to die with dignity.

The moral concern in going against the DNR order is based on the belief in the sanctity of human life, where the DNR order is associated with the possibility of healthcare provider abusing the patients leading to an earlier death ${ }^{38}$ and substandard care or even euthanasia. ${ }^{39}$ Some observational studies support this argument by associating the order of limiting life support with a higher incidence of mortality rate, ${ }^{40-42}$ whilst others do not support this finding. ${ }^{43}$ In 2006, the President of Hospice Patients Alliance President believed that DNR order might potentially harm the patient hence consequently raising the question about the morality in issuing the DNR order. ${ }^{38}$

"Some people should be
allowed to die when it truly
is the end. But that 'logic' can
be, and is abused. People are
interpreting the DNR
inappropriately up to the
extent that even minimal,
ordinary treatments like
providing food and water are
denied with the intent that
they die sooner."38

In other words, in a situation when the patient is mentally prepared to die, the healthcare provider might give less attention to them and eventually lead them to an earlier death. ${ }^{38}$ In the worst case scenario, the healthcare provider might think that care for these patients is a waste of time and resources since these patients have chosen to die.

Regarding the association between DNR order and euthanasia, it is worth to define this two term in the very basic concept. The former, allowing death 
to take place in the natural process which also provide the patient with dignity, ${ }^{23}$ while the latter enables death to happen by force with the intent to die faster ${ }^{44,45}$ such as withholding patient's ventilation and nutritional support to stop their breathing and letting them die of starvation. A patient with DNR status will continue to receive basic care ie oxygen therapy and nutrition. ${ }^{39,46}$ Death by euthanasia was said to have suffered more than DNR. ${ }^{44}$ However some studies indicated that euthanasia is painless. ${ }^{44,47}$

Nonetheless, the DNR order should not be associated with euthanasia unless the DNR order is misused or abused. Undoubtedly the act of abusing patients is immoral since the responsibility of a healthcare provider is to care for them by alleviating suffering and offer comfort before their demise. The concern here is, the action of selecting a patient to care for whilst neglected others is unjust and clearly immoral. Whilst appreciating the ethical principle of justice, a good moral conduct should be stressed to avoid unjust in patient care. Failing which a DNR order can be potentially associated with mercy killing when the nurses' act potentially causes death. ${ }^{48}$ In the event where the decision regarding the patient's end of life cannot be reached mutually between the patient and family members, the local law can come into effect in deciding the fate of the patient. ${ }^{49}$

\section{ISLAMIC PERSPECTIVE}

DNR order as part of the end of life issue is a hard undertaking to be discussed between healthcare provider, patient and family members. Local policies, legal requirements and guidelines are considered as useful tools to resolve this state of affairs. Nevertheless, these tools cannot be a complete answer because each patient is an individual and the tools might not be suitable for them. ${ }^{50}$ Islam encourages to save a life at all cost which is contrary to DNR. Islamic ethical framework, as a major concern here, should be studied as an alternative to analyse and provide a guideline for DNR according to the Islamic teaching. The Islamic perspective of DNR order should be highlighted from the concept of death, seeking for healing practices and requesting or refusing lifesaving intervention.

\section{Concept of Death}

A DNR order is like a death warrant. It is worth knowing the concept of dying before moving in depth to discuss the DNR order itself from the Islamic perspective. In the Qur'an, chapter 67 verses 1 and 2: "Blessed be He in Whose hands is Dominion: and He over all things has Power. He Who created Death and Life that He may try which of you is best in deed: and $\mathrm{He}$ is the Exalted in Might Oft-Forgiving", God mentions that He possesses the ability to make a life and expiry. Similarly, in the Qur'an, chapter 3 verse 145: "No soul can ever die except by Allah's leave, the term being fixed as by writing". This verse highlighted that only with the permission of God that any life may turn to a dead thing. Therefore, being alive or dead is the ultimate control of God. For example, some people may deliberately kill another, but the action does not mean the killer holds the sheer power over someone's life. However the action of killing only can be seen as a causal agent of mortality. After all, only with the permission of God will the victim be alive or dead.

However, in Islam, two criteria have been developed by scholars to confirm that one is dead. In the meeting of the Islamic Fiqh Council held during the third conference in 'Amman, the capital of the Hashemite Kingdom of Jordan from 11 to 16 October 1986, it was then decided that a person is considered to have died if one of the following two signs are proven:

1. If his heart and breathing have stopped completely and the physicians have determined that they cannot be resumed.

2. If all brain function has ceased completely, and the specialist, expert physicians have determined that this cessation is irreversible, and his brain has started to disintegrate. ${ }^{51,52}$

\section{Islamic View on CPR and DNR Order}

CPR is a medical intervention to revive a life in the event of cardiac or respiratory arrest. Hence prompt CPR may benefit the patient. The act of saving a life is a priority as emphasised in the Qur'an, chapter 5 verse 32: “And if anyone saved a life, it would be as if he saved the life of the whole people", where God mentions that saving a life is an obligation for everyone including one's own life and the life of others. This verse provides a general principle to show that life is sacred. Therefore, it is empirical to safe a patient's life via the means of CPR unless deemed harmful by the physician.

Founded along the principle of seeking healing practices, it is mandatory to seek treatment in lifethreatening illnesses. However, when the benefit of treatment is questionable, the act of seeking treatment becomes optional (harus). Moreover, if the treatment is perceived to be futile, hence it is not recommended to continue such treatment. ${ }^{27}$ As narrated by Imam Muhammad Ismail al-Mughirah alBukhari; "The Prophet Muhammad (SAW) forbade Muslims to contemplate death because the lifespan is likely to benefit either the opportunity to add his good deeds or forgiveness from God". Thus, while there are ways to save lives, these efforts need to be done". ${ }^{3}$ This can be reflected when CPR is given promptly to patients experiencing cardiac or respiratory arrest resulting in a better chance of survival with reduced risk of deficit.

With reference to this, Imam al-Ghazali wrote in his book; Ihya Ulumuddin, "Refusal of any treatment to save a life is forbidden ( $\square$ arām), if it 
results in the loss of life, just as one would take water for thirst and food for hunger". ${ }^{54}$ Thus, any attempt to refuse resuscitation or requesting to not resuscitate without a valid reason can be considered as immoral. As stated by Sheikh Muhammad alGhamidi, claims that whenever a physician opines that any medical treatment is likely to benefit and gives a chance of survival, automatically the ruling for seeking the treatment turn to compulsory. However, Sheikh Muhammad did not go far as to say that a person who refuses for medical treatment was considered as committing suicide. The person however would commit a sin, but not equally tough as the sin of someone who committed suicide. ${ }^{55}$ Likewise, patients with non-fatal medical conditions or no possibility of cardiac or respiratory arrest, but still requested for the DNR order is seen as immoral.

In accession, as a Muslim, Islam asks of its believers to remove any possible harm which could endanger one's life based on the principle of 'harm must be eliminated' (al--arar yuzāl). Therefore, it is unjust to leave cardiac or respiratory arrest untreated which could lead to death. Some may argue that CPR may introduce another harm such as broken ribs and pain due to intubation however, these are lesser harm as compared to death. It is also in line with the principle of 'the greater harm is removed by a lesser harm' (al-aarar al-ashadd yuzālu bi alaarar al-akhaf), the lesser harm is tolerated to eliminate the severity of the greater harm. ${ }^{56}$

If the patient is unlikely to benefit from CPR, the physician is obliged to withhold CPR attempt and issue the DNR order. ${ }^{48}$ Non-beneficial CPR would not change anything, the patient's condition may worsen such as leading a low quality of life requiring high expenses to keep the patient alive should the patient survive. ${ }^{57}$ With regards to this, Shaykh 'Abd al-'Azeez ibn 'Abd-Allaah ibn Baaz and Shaykh 'Abd al-Razzaaq 'Afeefi issued a fatwa in Fataawa al-Lajnah al-Daa'imah in year 1986, which provided several criteria in order to ensure the DNR is legally valid namely; when the patient's condition is not fit for resuscitation, patient is near death, patient has repeated arrests of the heart and lungs, patient's brain injury that cannot be treated, and no benefit in reviving the patient. For this, three trustworthy physicians must confirm these criteria before issuing a DNR order. ${ }^{51}$ According to Kasule in his article, DNR: An Islamic Formulation; he proposed four trustworthy physicians to confirm the appropriateness and relevance of DNR order based on the patient's condition, as the figurative four people were recognised as jamāaah (community) in the Islamic law. Thus, the presence of four individuals in this situation will be regarded as ijmar (a binding communal consensus) which is irrefutable and valid. ${ }^{48}$ Reflecting on the current conventional practice in Malaysia and abroad where only one physician decides on the fate of the patient is not in tandem with the Islamic guideline. Since this practice is bound to the standard operating orocedure or hospital guideline in the respective hospitals or countries, the suggestion to implement the Islamic guideline with reference to DNR should be put forth to the hospital or country policy makers.

For a terminally ill patient requesting DNR, this is legit in reference to the Islamic Religious Council of Singapore which states that it is permissible (mubah) in accordance to the Islamic ruling which respects the patient's request to deny intervention when terminally ill. However, this ruling is only applicable when the interventions are believed to sustain the organs but not to heal. ${ }^{58}$

If the physicians opine that the DNR order is the best option for the patient which may contradict the request of the patient and the family members, the physicians' opinion upholds because they are the expert in the area. Using the principle of "certainty cannot prevail doubt" (al-yaqīn lā yazūl bi al-shakk), a DNR order is legally valid if the physician believes that CPR would not yield any benefit to the patient. Shaykh 'Abd al-'Azeez ibn 'Abd-Allaah ibn Baaz and Shaykh 'Abd al-Razzaaq 'Afeefi issuing a fatwa in Fataawa al-Lajnah alDaa'imah in year 1986, stated:

"if reviving the heart and
lungs is of no benefit and not
appropriate because of a
certain situation, according
to the opinion of three
trustworthy specialist
doctors, then there is no
need to use resuscitation
equipment, and no attention
should be paid to the
opinions of the patient's next
of kin concerning the use of
resuscitation equipment or
otherwise, because this is not
their specialty." 1 .

In other words, the physician has the authority to issue a DNR order without the consent of the patient and their family members. Nevertheless, advance care directive which has been practiced worldwide that gives the patients and their families the higher authority to accept or refuse any medical intervention certainly contradicts with the Islamic perspective. On the other hand, in Kingdom of Saudi Arabia the DNR order is issued without consent from the patient and family members unlike the US. ${ }^{27}$

In summary, all arguments relating to this issue be referred to the fatwa issued by the Permanent Committee for Research and Fatwa in year 1989, Fatwa No. 12086, in response to the questions asked by the one of the military hospital in Saudi Arabia regarding CPR and DNR order. The following fatwa outlines the 'do not need CPR' hence a DNR order is allowed on patients;

a. If the patient is dead on arrival at the hospital, there is no need to revive the patient. 
b. If the patient's condition is not fit for resuscitation according to the medical report of three trustworthy specialist doctors, there is also no need to resuscitate the patient.

c. If the patient is suffering from a terminal sickness that is not responding to treatment and their end is certain, according to the testimony of three trustworthy specialist doctors, there is also no need to revive the patient.

d. If the patient is incapacitated or in a state of mental inactivity due to a chronic illness, or suffering from an advanced stage of cancer, a chronic heart or lung illness, or the recurrence of heart and lungs failure, and it is the decision of three trustworthy specialist doctors, there is also no need to resuscitate the patient.

e. If the patient shows evidence of untreatable brain damage, according to the medical report of three trustworthy specialist doctors, there is also no need to revive the patient.

$f$. If resuscitation of the heart and lungs will be inefficient and inappropriate in a specific instance, according to the medical judgment of three trustworthy specialist doctors, there is also no need to revive the patient. ${ }^{59}$

In summary, the findings showed the permissibility of the DNR from the Islamic perspective across all philosophy, jurisprudence and related ethical principles. Several important points may now be offered:

a. Firstly, though Islamic ethics and guidelines state that seeking for healing is optional, the ruling of seeking for healing may change to compulsory whenever the patient suffers from the life-threatening illness. As a Muslim, preserving life should be regarded as important as preserving others, such as religion, intellect, lineage and wealth. When physician opines that CPR is expected to be beneficial to pull through life, therefore refusing for the treatment may be consider as immoral.

b. Secondly, on the importance of CPR for cardiac or respiratory arrest situation, undoubtedly CPR is recognised as an immediate response intervention to prolonge the patient's life span. On the other hand, DNR order is called for if the doctor believes that CPR would be futile and has no benefit to the patient with terminal illness, late stage cancer, or patients who are dying. Therefore, performing non-beneficial CPR on these patients is not allowed in line with the principle of harm prevention. On the contrary, in a small number of cases, the western practices allowed non-beneficial CPR on such patients for the sake of caring and compassion. ${ }^{60}$

c. Thirdly, the physician has the authority to issue a DNR order if CPR is futile for the patient. This order can be done without getting consent from the patient and their family members as the physician is the expert in the field. This fatwa is contrary to the practices in the US where patient's and family wishes are considered a top priority ${ }^{61,62}$. The outcome of the survey led by Lisa et al in 1993 amongst US nurses has supported this statement, whereby $70 \%$ of the respondents declared any decision regarding DNR should be in accordance with the autonomy of the patient. ${ }^{63}$

\section{CONCLUSION}

Therefore, why are resuscitation issues so important to nurses? Nurses play an active role to facilitate the decision on end of life issues by actively taking part in the discussions, constantly reviewing the DNR order in long-term care facilities and deciding the proper intervention at the arrest scene. ${ }^{57}$ Apart from that, some suggests that nurses are also qualified to issue the DNR order since they have continuous contact with the patient and perhaps understand the patient's preference better. ${ }^{26}$ Without the involvement of nurses, it is hard to achieve mutual understanding between two parties ie physicians and patients, in making a decision. Therefore, nurses would need additional education and updates regarding the law, acts and bills on end of life treatments ${ }^{33}$ in order to help them in forming moral judgments and preparing them with relevant information.

The findings of this study can aid the growth of related knowledge among nurses and lead towards the enrichment of knowledge in nursing, especially the permissibility of DNR from an Islamic perspective. Few studies have shown that the perspective of religion on the matter discussed play a major role amongst the patients to perceive the illness and to make an informed decision. ${ }^{64,65}$ Indeed, a local study carried out amongst outpatients at the University Malaya Medical Centre, Malaysia showed the majority of the patients mainly Muslim pointed out that every health plan needs to be in line with their religious views. ${ }^{66}$ Since the nurses facilitate individuals in making a decision as they engage in nursing care, by using a comprehensive view of the DNR based on the Islamic teaching would provide an informed choice when advising a Muslim patient and family. For the future direction of this study, the investigation to explore the knowledge of Islamic moral judgment on this issue among nurses is highly recommended.

\section{REFERENCES}


1. Mayor M Macmillan English Dictionary for

Advanced Learners. Oxford: Macmillan

Publisher Limited; 2002.

2. resuscitate. The American Heritage $\AA$ Science Dictionary. Hought. Mifflin Co. Available at: http://www.dictionary.com/browse/ resuscitate. Accessed April 13, 2016.

3. Ballinger J, Barnett $\mathrm{H}$, Bognolo $\mathrm{G}$, et al. Black's Medical Dictionary 42nd Edition. (Marcovitch H, ed.). A \& C Publishers Ltd; 2010.

4. New York State Department of Health. Your Rights as a Hospital Patient in New York State. 1997. Available at: https:// www.health.ny.gov/publications/1449.pdf.

5. Peberdy MA, Kaye W, Ornato JP, et al. Cardiopulmonary resuscitation of adults in the hospital: A report of 14720 cardiac arrests from the National Registry of Cardiopulmonary Resuscitation. Resuscitation 2003;58(3):297308.

6. Omnibus Budget Reconciliation Act of 1990. 2009. Available at: http://psychrights.org/ education/ModelQuiTam/Legislation/ HRConfRep101-964.pdf.

7. Mental Capacity Act 2005 - Code of Practice. London, United Kingdom: The Stationery Office on behalf of the Department for Constitutional Affairs; 2007.

8. Puteri Nemie Jahn Kassim, Fadhlina Alias Advance Directives for Medical Treatmenta: The Current Legal Status. Malayan Law J. 2015;3:i-xx.

9. Morrison LJ, Kierzek G, Diekema DS, et al. Part 3: Ethics 2010 American Heart Association Guidelines for Cardiopulmonary Resuscitation and Emergency Cardiovascular Care. Circulation 2010;122(suppl 3):S665-S675.

10. United States General Accounting Office. Providers Offer Information on Advance Directives but Effectiveness Uncertain. Washington DC; 1995. Available at: https:// www.gpo.gov/fdsys/pkg/GAOREPORTS-HEHS95-135/pdf/GAOREPORTS-HEHS-95-135.pdf.

11. Moye J, Sabatino CP, Weintraub Brendel R. Evaluation of the capacity to appoint a healthcare proxy. Am. J. Geriatr. Psychiatry 2013;21(4):326-36. doi:10.1016/ j.jagp.2012.09.001.

12. Silveria MJ, Kim SYH, Langa KM Advance Directives and Outcomes of Surrogate Decision Making before Death. N. Engl. J. Med. 2010;362(13):1211-1218. Available at: http:// www.nejm.org/doi/pdf/10.1056/ NEJMsa0907901.

13. Emanuel EJ, Hummel LR How Well is the Patient Self-Determination Act Working?: An Early Assessment. Am. J. Med. 1993;95:619628.

14. Hanson LC, Danis M, Mutran E, Keenan NL, Hill C. Impact of Patient Incompetence on Decisions To Use or Withhol Life-Sustaining Treatment Am J Med. 1994;97:235-241.

15. Sittisombut $S$, Love EJ, Sitthi-Amorn C Attitudes toward advance directives and the impact of prognostic information on the preference for cardiopulmonary resuscitation in medical inpatients in Chiang Mai University Hospital, Thailand. Nurs. Health Sci. 2005;7 (4):243-50.

16. Enohumah KO, Moerer O, Kirmse C, Bahr J, Neumann P, Quintel M. Outcome of cardiopulmonary resuscitation in intensive care units in a university hospital. Resuscitation 2006;71(2):161-70.

17. Landry FJ, Parker JM, Phillips YY. Outcome of cardiopulmonary resuscitation in the intensive care setting. Arch. Intern. Med. 1992;152 (11):2305-8.

18. McNally B, Robb R, Mehta M, et al. Out-ofhospital cardiac arrest surveillance-Cardiac Arrest Registry to Enhance Survival (CARES), United States, October 1, 2005-December 31, 2010. MMWR Surveill Summ 2011;60(8):1-19.

19. Coburn DR. In re Quinlan口: A Practical Overview. Ark. Law Rev. 1977;31(1):59-74.

20. Clark GD, Lucas K, Stephens L. Ethical dilemmas and decisions concerning the do-notresuscitate patient undergoing anesthesia $\mathrm{J}$ Am Assoc Nurse Anesth. 1994;62(3):253-256.

21. Edwards DM, Logue GL, Nelson W, et al. Do-Not -Resuscitate Orders and Medical Futility. Arch Intern Med 2003;163(22):2689-2694.

22. Reynolds J, Croft S. Cardiopulmonary resuscitation in end of life care. Nurs. Stand. 2012;26(51):35-42.

23. Venneman SS, Narnor-Harris $P$, Perish $M$, Hamilton M. "Allow natural death" versus "do not resuscitate": three words that can change a life. J. Med. Ethics 2008;34(1):2-6.

24. Breault JL. DNR, DNAR, or AND? Is Language Important? Ochsner J. 2011;11(4):302-306.

25. Keffer MJ, Keffer HL. Do-Not-Resuscitate in the Operating Room: Moral Obligations of Anesthesiologists. Anesth. Analg. 1992;74 (6):901-905.

26. Burkhardt MA, Nathaniel AK. Ethics \& Issues in Contemporary Nursing. 3rd Ed. Clifton Park, New York: Thomson Delmar Learning; 2008.

27. Saleen Saiyad Do Not Resuscitate: A Case Study from the Islamic Viewpoint J Islam Med. Assoc. North Am. 2009;41:109-113.

28. Layon AJ Resuscitation and DNRa: ethical aspects for anaesthetists. Can. J. Anaesth. 1994;42(2):134-140.

29. Braddock $\mathrm{CH}$, Derbenwick J Do Not Resuscitate (DNAR) Orders. Univ. Washingt. 2014. Available at: https: / /depts.washington.edu/bioethx/ topics/dnr.html.

30. Hilberman M, Kutner J, Parsons D, Murphy DJ. Marginally effective medical care : ethical analysis of issues in cardiopulmonary resuscitation (CPR) J Med. Ethics 1997;23:361367.

31. Mullen M a, Gow RM. Understanding ethical issues, ICD, and DNR orders: an obstacle to imminent death? Heart Rhythm 2010;7(6):85860.

32. Fitzgerald DJ, Milzman DP, Sulmasy DP Creating a Dignified Option: Ethical Considerations in 
the Formulation of Prehospital DNR Protocol.

Am. J. Emerg. Med. 1994;13(2):223-228.

33. Saevareid TJ, Balandin S. Nurses' perceptions of attempting cardiopulmonary resuscitation on oldest old patients. J. Adv. Nurs. 2011;67 (8):1739-48.

34. Calam B, Andrew R CPR or DNR? End of Life Decision Making on a Family Practice Teaching Ward. Can. Fam. Physician 2000;46:340-346.

35. Rapoport J, Teres D, Lemeshow S Resource use implications of do not resuscitate orders for intensive care unit patients. Am. J. Respir. Crit. Care Med. 1996;153(1):185-90.

36. Bion J Rationing Intensive Care BMJ Br. Med. J. 1995;310(6981):682-683.

37. Muller D Do NOT Resuscitate. Health Aff. (Millwood). 2005;24(5):1317-22.

38. Panzer R Hospice Patients Alliance - Dancing with Death. 2006. Available at: http:// www.hospicepatients.org/dancing-withdeath.html.

39. Downar J, Luk T, Sibbald RW, et al. Why do patients agree to a "Do not resuscitate" or "Full code" order? Perspectives of medical inpatients. J. Gen. Intern. Med. 2011;26(6):582 $-7$.

40. Cheng Y-Y, Connors AF, Garland A Effect of Decisions to Withhold Life Support on Prolonged Survival. Chest 2008;133(6):13121318.

41. Azoulay E, Pochard F, Garrouste-Orgeas M, et al. Decisions to forgo life-sustaining therapy in ICU patients independently predict hospital death. Intensive Care Med. 2003;29(11):1895901.

42. Shepardson LB, Youngner SJ, Speroff T, Rosenthal GE. Increased risk of death in patients with do-not-resuscitate orders. Med. Care 1999;37(8):727-37. Available at: http:// www.ncbi.nlm.nih.gov/pubmed/10448716. Accessed August 21, 2016.

43. Prendergast TJ, Claessens MT, Luce JM A national survey of end-of-life care for critically ill patients. Am. J. Respir. Crit. Care Med. 1998;158(4):1163-7.

44. Beauchamp TL, Davidson Al The Definition of Euthanasia J Med Philos. 1979;4(3):294-312.

45. Vilela LP, Caramelli P Knowledge of the Definition of Euthanasia: Study with Doctors and Caregivers of Alzheimer's Disease Patients. Rev Assoc Med Bras 2009;55(3):263-267.

46. Lippert FK, Raffay V, Georgiou M, Steen PA, Bossaert L European Resuscitation Council Guidelines for Resuscitation 2010 Section 10 . The ethics of resuscitation and end-of-life decisions. J. Resusc. 2010;81:1445-1451.

47. Abdurezak Abdulahi Hashi Bioethics: A Comparative Study of Its Concepts, Issues and Approaches. First Ed. Gombak: IIUM Press; 2015.

48. Kasule OH DNR: An Islamic Formulation. J. Islam. Med. Assoc. North Am. 2010;42:36-37.

49. Irwin A, Wand D Do not attempt resuscitationa: the legal issues. Nurs. Resid. Care 2014;16 (8):464-467.
50. Kasule $\mathrm{OH}$ Ethical Issues in Emergency Care and Research J T U Med Sc 2011;6(2):78-85.

51. Shaykh Muhammad Saalih al-Munajjid. Islam Question and Answer. 2016;(April). Available at: https://islamqa.info/en/115104.

52. Abul Fadl Mohsin Ebrahim Islamic Jurisprudence and the End of Human Life. Med Law 1998;17:189-196.

53. Imam Muhammad Ismail al-Mughirah alBukhari. The Translation of the Meanings of Sahih Al-Bukhari. Riyadh, Saudi Arabia: Darussalam; 1997.

54. Imam al-Ghazali Revival of Religious Learnings Imam Ghazali's Ihya Ulumuddin. Karachi, Pakistan: Darul-Ishaat; 1993.

55. Sheikh Muhammad al-Ghamidi Refusing surgery needed to stay alive. Islam Today. Available at: http://en.islamtoday.net/node/1343.

56. Azman Ismail, MD Habibur Rahman Islamic Legal Maxim: Essential and Applications. First Ed Kuala Lumpur: IBFIM; 2013.

57. Greenlaw J Orders Not to Resuscitate $:$ Dilemma for Acute Care as well as Long Term Care Facilities. NLE Rounds 1982:29-45.

58. Majlis Ugama Islam Singapura (MUIS). Isu Arahan Awal Perubatan (Advance Medical Directive ). 2015. Available at: http:// www.officeofthemufti.sg/Fatwa/isu-arahanawal-perubatan(amd)(mly).html.

59. Permanent Committee for Research and Fatwa. Fatwas on Medical Issues and the Sick. Dept Relig. Sci. Res. Fatwa, Riyadh 1989:322324. Available at: http://www.alifta.com/ Search/ResultDetails.aspx? languagename $=$ en\&lang $=$ en\&view $=$ result\&fat $w$ aNum=true\&FatwaNumID=12086\&ID=9767\&sear chScope $=7 \&$ SearchScopeLevels $1=\&$ SearchScope Levels2=\&highLight $=1 \&$ SearchType $=$ EXACT\&Sea rchMoesar=false\&bookID=\&Left Val=0\&RightVal =0\&s. Accessed August 20, 2016.

60. Truog RD Is It Always Wrong to Perform Futile CPR? N. Engl. J. Med. 2010;362(6):477-479.

61. Saeed F, Kousar N, Aleem S, et al. End-of-life care beliefs among Muslim physicians. Am. J. Hosp. Palliat. Care 2015;32(4):388-92.

62. Murphy PA. The Nurse's Role in End of Life Decisions J Burn Care Rehabil. 1994;15(1):8485.

63. Marchette L, Ph D, Hennessy M, Wasserlauf $M$. Nurses' perceptions of the support of patient autonomy in do-not- resuscitate (DNR) decisions. Int J Nurs Stud 1993;30(1):37-49.

64. Stein EM, Kolidas E, Moadel A Do spiritual patients want spiritual interventions?: A qualitative exploration of underserved cancer patients' perspectives on religion and spirituality. Palliat. Support. Care 2015;13 (1):19-25.

65. Tumwesigye NM, Atuyambe L, Kibira SPS, Wabwire-Mangen $F$, Tushemerirwe $F$, Wagner GJ Do religion and religiosity have anything to do with alcohol consumption patterns? Evidence from two fish landing sites on Lake Victoria Uganda. Subst. Use Misuse 2013;48 (12):1130-7. 
66. Htut $Y$, Shahrul K, Poi P The Views of Older Malaysians on Advanced Directive and Advanced Care Planning: A Qualitative Study. Asia-Pacific J. Public Heal. 2007;19(3):58-66. 
